\title{
The Psychometric Properties of the Mindfulness in Teaching Scale in a Turkish Sample
}

\author{
Meltem Aslan Gördesli, Reyhan Arslan, Ferah Çekici, Zeynep Aydin Sünbül, Asude Malkoç \\ School of Education, Istanbul Medipol University, Turkey
}

Copyright $\subseteq 2019$ by authors, all rights reserved. Authors agree that this article remains permanently open access under the terms of the Creative Commons Attribution License 4.0 International License

\begin{abstract}
In this study, by translating the Mindfulness in Teaching Scale (MTS) developed by Frank, Jennings and Greenberg [1] into Turkish, it was aimed to investigate the psychometric properties of the Turkish version of the scale among Turkish educators. The adaptation study of the scale started with the linguistic equivalence study. After revealing that the scale was equivalent to the original form linguistically, Confirmatory Factor Analysis (CFA) was applied for the construct validity. As a result of CFA, it was observed that the two-factor structure of goodness of fit was excellent ( $\mathrm{c} 2 / \mathrm{sd}=2.111$, IFI $=.93, \mathrm{CFI}=.93, \mathrm{GFI}=.95$ and RMSEA $=.054$ ) whereas the single factor structure was at acceptable level $(\mathrm{c} 2 / \mathrm{sd}=2.982, \mathrm{IFI}=.87, \mathrm{CFI}=.87$, GFI $=.93$ and $\mathrm{RMSEA}=.072$ ) based on the compliance index value calculations. The Cronbach's-alpha internal consistency coefficient was found to be .64 for the Interpersonal Mindfulness subscale, .80 for the Intrapersonal Mindfulness subscale, and .78 for the whole scale. While the corrected item total correlations ranged from .30 to .65 , it was found that t-test results for the scores of the upper $27 \%$ and lower $27 \%$ groups were significant, and the scale indicated significant relationships with the Mindful Attention Awareness Scale (MAAS) ( $<<.05)$. In order to determine the test-retest reliability, correlation coefficient was found to be statistically significant in accordance with the measurements made in 3-week interval. Overall findings demonstrated that the Mindfulness in Teaching Scale is a valid and reliable measurement tool for Turkish educators.
\end{abstract}

Keywords Mindfulness in Teaching Scale, Validity, Reliability

\section{Introduction}

Educators pursue their educational activities in the classes, which are composed of students with different emotional, social and academic needs. The challenges of the situation that the maintenance of educational activities in different fields and heterogeneous groups with various needs are obvious. The teaching profession was shown as one of the high-risk occupational groups - based on the results of the work of the American Stress Institute - to jeopardize health and to make it hard to struggle with daily life problems [2]. Studies conducted in educational organizations show that teachers are under an excessive workload, and one third of them suffer from stress and burn out $[3,4,5]$. It is a well-known premise that negative emotions such as stress and burnout experienced by educators are related with classroom climate and negative behaviors of students [6] as well as with anger and anxiety feelings of students who perceive the behaviors of teachers negatively; therefore, related with low motivational levels, too [7]. Teachers' personal stress and work-related emotional exhaustion are known to hinder their ability to provide consistent emotional support and positive behavior management that children need for their positive social-emotional development [8]. Therefore, the recent studies focus on protective factors against the risk factors faced by educators. Since the professional or emotional problems experienced by the educators in the classroom are reflected in the classroom environment and can negatively affect the educational activities. For example, teacher's emotional and behavioral competences, such as well-being, emotional and professional self-efficacy and their prosocial behaviors[9]. Furthermore, it is supported by various studies that those competencies promote educator-student relationship in a supportive manner, provide effective classroom management and increase socio-emotional learning in positive behaviors $[10,6]$. The results of the studies indicate that being resilient to socio-emotional risk factors and having positive socio-emotional competencies are very crucial for the educator to have personal well-being, to improve the effectiveness of teaching activities and classroom management.

In recent years, it was observed that mindfulness gained an important place in the studies conducted in order to reduce the impact of the socio-emotional risk factors experienced by educators and to support the positive 
education-learning environments. Kabat-Zinn [11] defines mindfulness as focusing attention on the experiences that are occurring at the moment. According to Germer et al. [12] mindfulness is related to decreasing the level of pain and increasing our well-being in all experiences which are positive, negative or neutral. This specific way of consciousness is balancing one's negative feelings and thoughts, in other words, neither excessive identification with them, nor letting oneself go with these negative emotions and thoughts. According to the Buddhist psychological model [13], mindfulness reduces the clinical symptoms of individuals and increases the well-being by providing conscious awareness, acceptance/compassion, and attention regulation.

Several studies revealed that educators' awareness is negatively correlated with burnout [14] and stress levels [15]. Napoli [16], based on the result of his interviews with teachers, suggested that teachers use their awareness skills (a) to help in curriculum development and implementation, (b) to deal with conflict and anxiety, (c) to improve the quality of their personal lives, and (d) to facilitate positive changes in the classroom. While mindfulness-based stress reduction programs for educators provide a reduction in burnout, stress and various psychological symptoms of educators; the increase in personal qualities such as self-compassion and attention has been observed $[17,18$, 19]. It is also known that conscious awareness programs for educators provide a reduction in students' compelling behaviors and negative social interactions [20] and an increase in classroom management skills [14]. The effects of the educator's mindfulness on the individual characteristics as well as on the classroom environment and the student behavior are quite remarkable.

According to Khoury [21], the attention and awareness mechanisms underlying all definitions of conscious awareness, from the eastern or western perspective, combine both internal processes (e.g. bodily sensations) and external stimuli (e.g. social / interpersonal interactions). Therefore, awareness can be perceived equally as a personal and interpersonal process. However, when the literature on mindfulness is examined, it is observed that social effects of personal mindfulness are more emphasized whereas the investigation of mindfulness in a social context remains limited. Langerian mindfulness, also called as social-cognitive awareness, examined mindfulness in social context, and revealed that the consequences of some social behaviors were related to mindfulness. However, there is a limited number of studies on the interpersonal aspect of mindfulness. Especially, the limitation of the measurement tools developed for the purpose of examining the interpersonal mindfulness in social contexts is considered to be an important determinant at this point. Nevertheless, the development of two measurement tools related to the social aspect of awareness in recent years is a promising step in this regard. In order to enable mindfulness to be measured in social context, measurements of mindfulness in parenting and mindfulness in teaching have been encountered.

The Mindfulness in Teaching Scale, which is important for interpersonal mindfulness and measures mindfulness in teaching processes, was developed by Frank, Jennings and Greenberg[1]. The original form of the scale is composed of 2 factors and 14 items, and the internal consistency coefficient is over .70 for the subscales. Considering both the therapeutic effects of mindfulness on educators and the importance of it in interpersonal processes; in this study, the adaptation process of the Mindfulness in Teaching Scale for Turkish educators was conducted.

\section{Materials and Methods}

\subsection{Participants}

The population of this study consists of 7681 Turkish educators who conduct their educational activities in Kadıköy and Ataşehir districts of İstanbul. The sample of the study that was selected through convenient sampling method consists of 409 educators working in different education levels. Of the teachers who participated in the study, $78.9 \%(\mathrm{n}=302)$ are female and $21.1 \%(\mathrm{n}=107)$ are male. The age range of the participants is between 22-64 along with the mean age of 42 , of the participants, $7.3 \%$ (n $=30)$ are working in kindergarten, $31.3 \%(\mathrm{n}=128)$ in primary school, $34.2 \%$ in secondary school $(\mathrm{n}=140)$, and $27.1 \%(\mathrm{n}=111)$ in high school.

\subsection{Materials}

In order to collect the data on the socio-demographic variables of the participants, the Personal Information Form developed by the researchers was used together with the Mindful Attention Awareness Scale [22] and the Mindfulness in Teaching Scale [1]. Information about the measurement tools used in the research is presented below.

\subsubsection{Mindful Attention Awareness Scale (MAAS)}

Mindful Attention Awareness Scale (MAAS) developed by Brown and Ryan [22] is a 15-item scale that measures the general tendency to be aware of instant experiences in daily life and to pay attention to those experiences. MAAS has a single factor structure and gives a single total score. High scores obtained from the scale indicate high levels of mindfulness. Both constructive and confirmatory factor analyses were performed to determine the construct validity of MAAS. In exploratory factor analysis, it was confirmed that MAAS has a single factor structure. Factor loadings vary between .27 and .78 . According to the results of confirmatory factor analysis, compliance indices confirmed that MAAS showed single-factor structure. $(\mathrm{c} 2 / \mathrm{sd})=189.57 / 90$, GFI; .92, CFI:.91, RMSEA:.058). The scale has the internal consistency coefficient of .82 ; the 
total correlations of the obtained items ranged between .25 and .72 . Test-retest reliability of MAAS was found as .81 . For the criterion-related validity of MAAS; Big Five Personality Traits, State Mood Inventory, Mindfulness/Mindlessness Scale and Self-consciousness Scale were used and significant relationships were determined between them [22].

The Turkish adaptation study of the Mindful Attention Awareness Scale (MAAS) was carried out by Özyeşil, Arslan, Kesici and Deniz [23]. According to the compliance statistics based on the confirmatory factor analysis results of MAAS ( $22=187.811, \mathrm{sd}=90, \mathrm{c} 2 / \mathrm{sd}=$ $2.086, \mathrm{p}<.01)$, the scale showed a one-dimensional structure and had a goodness of fit which is an acceptable model. In the item-total correlations, all items of MAAS were over .40. The factor loadings of MAAS for each item ranged from .484 to .805 . In order to determine the reliability of the scale, Cronbach Alpha internal consistency coefficient calculated as .80 and test-retest correlation was found as .86 depending upon item analysis.

\subsubsection{Mindfulness in Teaching Scale (MTS)}

The scale was developed by Frank, Jennings and Greenberg [1] in order to measure the teachers' mindfulness during the teaching processes. The original form of the scale consists of 14 items. After the validity and reliability analysis conducted with 397 teachers, the scale was reported to consist of 2 factors which were "intrapersonal" and "interpersonal" mindfulness. Cronbach Alpha internal consistency coefficients were found to be .861 for "Intrapersonal Mindfulness" and .711 for "Interpersonal Mindfulness". As a result of exploratory factor analysis, it was observed that the factor loadings ranged between .830 and .432 . The two-factor structure yielded from Exploratory Factor Analysis (EFA) was tested with the Confirmatory Factor Analysis and this structure was found to be perfectly compatible with the data $\left(\chi^{2}=105.36, \quad \mathrm{p}=0.015, \quad\right.$ TLI $=0.969, \quad \mathrm{CFI}=0.974$, RMSEA $=0.038$ ). For criterion validity of the original scale, Mindful Attention Awareness Scale (MAAS), Maslach Burnout Inventory (MBI), Teacher Socio-Emotional Self-Efficacy Scale and Teachers Behavior Management Self-Efficacy Scale. As a result of criterion validity study, it was discovered that the original scale was significantly correlated with all of these constructs. A 6-month test-retest reliability was also indicated to be statistically significant.

The Korean version of Mindfulness in Teaching Scale (MTS) indicated a 2-factor structure just as the original scale. The results of confirmatory factor analysis (CFA), monitored that each subscale had satisfactory internal consistency. The subscales were positively associated with mindfulness, teacher competence and occupational satisfaction whereas negatively associated with occupational stress and teacher burnout [24].

\subsection{Procedure}

After the required permissions were obtained from the Istanbul Governorship and Istanbul Provincial Directorate of National Education, the study was conducted with the teachers on a volunteer basis who had been working in various educational levels in Istanbul. A total of 409 teachers participated in the study.

\subsection{Data Analysis}

Confirmatory factor analysis was applied in order to test the convenience of the original factor structure of the Mindfulness in Teaching Scale to Turkish teachers. Firstly, missing values were scanned in order to make data to fit CFA and it was observed that the number of cells belonging to these values was below $5 \%$. The data of 22 participants were excluded from the analysis together with the participants who indicated extreme values for the criterion of CFA assumptions and those who did not meet the criteria for $Z$ score \pm 3.29 [25]. Lastly, the normality assumption of CFA was determined by scanning the skewness and kurtosis parameters while the linearity assumption was analyzed by the distribution graph. As a result, it was found that the data had a normal and linear distribution for the sample [26].

Corrected item-total score correlations were calculated in order to determine how sufficient the items in the subscales were to differentiate individuals in terms of the characteristics they measured. Then, the relationship between the lower $27 \%$ and the upper $27 \%$ groups was investigated. The reliability of the scale was analyzed by Cronbach alpha internal consistency coefficient and test-retest correlation.

\section{Findings}

The findings obtained as a result of the analyses made for the adaptation of the Mindfulness in Teaching Scale into Turkish are presented below.

\subsection{The Translation of the Mindfulness in Teaching Scale into Turkish}

The translation of the Mindfulness in Teaching Scale (MTS) into Turkish which the original form of is English firstly done by the authors. The convenience of both translation and measurement tool was evaluated by five experts at the $\mathrm{PhD}$ level. Following the corrections made in line with the feedback received from the experts, the opinions of a Turkish linguist from the Turkish language field and the remarks of the two measurement-evaluation experts on the form, the material structure and the rating of the inventory were taken. The scale was not back translated into English in order to avoid item bias [27]. 


\subsection{Validity and Reliability Analysis Findings of the Mindfulness in Teaching Scale}

Confirmatory factor analysis was conducted for the construct validity of the Turkish inventory. In order to test the convergent validity, the relationship of the scale with Mindful Attention Awareness Scale (MAAS) was examined. After validity studies, reliability analyses were performed. The internal consistency coefficient was calculated to determine the reliability of MTS. The relation between the lower $27 \%$ group and the upper $27 \%$ group, and test-retest correlations were investigated.

\subsubsection{Findings Regarding Validity}

Findings of Confirmatory Factor Analysis (CFA). The original factor structure of the MTS was tested with CFA. First of all, compliance statistics were conducted for the two latent variable (two-factor) model, as in the original scale. The goodness of fit index values were also examined. The criterion indices used to test the goodness of fit of the scale are normed chi square value, Tucker-Lewis index (TLI) and comparative fit index (CFI), root mean square error of approximation (RMSEA) and goodness of fit index (GFI) [25]. Firstly, $2^{\text {nd }}$ item with factor loading below .30 was removed from the further analyses. Since the error covariance of two item pairs was found to be high, those item pairs were linked together as those items can be regarded as culturally close to each other. And in the final stage, along with these adjustments, the goodness of fit values were found as $\mathrm{c} 2 / \mathrm{sd}=2.111, \mathrm{IFI}=.93, \mathrm{CFI}=.93$, $\mathrm{GFI}=.95$ and RMSEA $=.054$. In the two-factor model, the factor loadings ranked between .30 and .70. In the CFA analysis conducted to test the single factor structure of the scale (General Mindfulness in Teaching), the goodness of fit values were found as $\mathrm{c} 2 / \mathrm{sd}=2.982, \mathrm{IFI}=.87, \mathrm{CFI}=.87$, $\mathrm{GFI}=.93$ and $\mathrm{RMSEA}=.072$ for the 13 item single factor structure after the $2^{\text {nd }}$ item with factor loading below .30 was removed and the necessary modifications were made. It was observed that the factor loadings of the General Mindfulness in Teaching test were found to be .30 and above except for 2 items (item $4=.25$ and item $6=.26$ ). According to the fit indices, being c2/sd below 3 [25] and being RMSEA below .08 indicates the acceptability of both models whereas CFI, GFI and AGFI values are in the range of .90-1.00 as expected in a two-factor model showing that the single-factor model partially met this criterion.

Convergent validity findings. For the convergent validity of MTS, the relationship between the scale and MAAS was examined. According to the results of Pearson Correlation Analysis, it was found that the total score of MAAS was correlated with the subscale scores of MTS Intrapersonal Mindfulness subscale as $r=.619$, is correlated with Interpersonal Mindfulness subscale scores as $\mathrm{r}=.178$ and is correlated with total score of MTS as $\mathrm{r}=.581$ $(\mathrm{p}<.001)$. When the correlations between subscales and the total scores of MTS were examined, the intrapersonal ( $\mathrm{r}$ $=.65)$ and the interpersonal mindfulness subscales correlations ( $\mathrm{r}=.93)$ were strong; however, it was observed that the two subscales were correlated with each other at moderate level ( $\mathrm{r}=.32)$.

\subsubsection{Findings Related to Reliability}

MTS Cronbach Alpha Internal Consistency Coefficient Findings. The internal consistency coefficient of MTS was calculated separately for the two factors as well as for the whole scale. As a result of the conducted analyses, it was found that the Cronbach alpha internal consistency coefficient was .80 for Intrapersonal Mindfulness subscale, was .64 for the Interpersonal Mindfulness subscale, and was .78 for the whole scale.

MTS T-Test Findings for Comparison of Upper 27\% and Lower 27\% Groups. The results of the t-test conducted to analyze the significance of the difference between MTS corrected item total correlations and the mean score of the upper $27 \%$ and the lower $27 \%$ groups are presented in Table-1.

Table 1. Independent Group T-Test for the Comparison of Upper 27\% and Lower 27\% Groups and Item Total Correlations

\begin{tabular}{|c|c|c|c|}
\hline Factor & Item No. & $\begin{array}{c}\text { Item Total } \\
\text { Correlations } \\
\end{array}$ & $\begin{array}{c}\text { T (upper \%27 } \\
\text {-lower\%27) }\end{array}$ \\
\hline \multirow[t]{9}{*}{ Intrapersonal } & 1 & .304 & $8.336 * * *$ \\
\hline & 7 & .532 & $11.124 * * *$ \\
\hline & 8 & .535 & $11.978 * * *$ \\
\hline & 9 & .454 & $14.641 * * *$ \\
\hline & 10 & .645 & $19.195 * * *$ \\
\hline & 11 & .475 & $20.697 * * *$ \\
\hline & 12 & .624 & $13.647 * * *$ \\
\hline & 13 & .425 & $11.663 * * *$ \\
\hline & 14 & .481 & $9.605 * * *$ \\
\hline \multirow[t]{4}{*}{ Interpersonal } & 3 & .473 & $11.131 * * *$ \\
\hline & 4 & .373 & $12.048 * * *$ \\
\hline & 5 & .514 & $11.685 * * *$ \\
\hline & 6 & .328 & $12.048 * * *$ \\
\hline
\end{tabular}

$* * * \mathrm{p}<.001$

MTS Test-Retest Reliability. For the test-retest study, the measurement tool was administered to a group of 30 people at 3-week intervals. Based on the result of the Pearson product-moment correlation coefficient, the test-retest coefficients were found to be $r=.88(p<.001)$ for the Interpersonal Mindfulness subscale, $r=.58(\mathrm{p}<.01)$ for the Intrapersonal Mindfulness subscale, and $\mathrm{r}=.83$ for the total score of the scale $(\mathrm{p}<.001)$.

\section{Discussion}

In this research, the adaptation study of the Mindfulness in Teaching Scale-MTS [1] that measures the mindfulness of educators in educational environments was conducted for Turkish educators. In this context, for the adaptation of 
the original scale in Turkish sample (i) CFA, (ii) convergent validity, (iii) internal-consistency coefficient, (iv) independent group $t$ test comparing upper-lower $27 \%$ groups, and (v) test-retest score correlations were examined.

Following the linguistic equivalence study, CFA was conducted to test the two-factor structure of the original scale. In the first part, item factor loadings were examined and then $2^{\text {nd }}$ item having factor loading below .30 was excluded from the analysis (Brown, 2006). After this process, the model was tested and the two factor pairs with high error covariance with each other in the two-factor model were linked together, and the analysis was continued. Results indicated that the 2-factor model was very well adapted into the Turkish sample $(\mathrm{c} 2 / \mathrm{sd}=2.111$, IFI $=.93$, $\mathrm{CFI}=.93, \mathrm{GFI}=.95$ and RMSEA $=.054)$ and item factor loadings were all above .30 . It was observed that the single factor structure of the scale (Global Mindfulness in Teaching) was also at acceptable levels ( $\mathrm{c} 2 / \mathrm{sd}=2.982$, IFI $=.87, \mathrm{CFI}=.87, \mathrm{GFI}=.93$ and $\mathrm{RMSEA}=.072$ ). Due to the broadband nature of mindfulness as a measured construct, two items with the factor loadings being less than .30 were also kept in the scale [28].

The convergent validity study of the scale was performed with MAAS. Significant positive correlations were found between MAAS scores and the Intrapersonal Mindfulness subscale $(\mathrm{r}=.619)$, the Interpersonal Mindfulness subscale $(r=.179)$, and the total score of mindfulness in teaching $(\mathrm{r}=.581)(\mathrm{p}<.05)$. In the adaptation study of the original scale to the Korean sample, the correlation coefficient between mindfulness and Intrapersonal Mindfulness subscale was found as .572, between mindfulness and the Interpersonal Mindfulness subscale as .359 , and between mindfulness and total score of Mindfulness in Teaching Scales .598 [24]. The relationship of general mindfulness to the Intrapersonal Mindfulness subscale and the total score of the MTS were found to be strong in Turkish version as it was also the case in the Korean version of the scale.

When the correlations between the total score of MTS and the subscales were examined, it was explored that the total score had strong correlation with both Intrapersonal ( $\mathrm{r}$ $=.65)$ and Interpersonal Mindfulness subscales $(r=.93)$. However, the two subscales were correlated with each other at moderate levels $(\mathrm{r}=.32)$. The result that the correlation coefficient between the Intrapersonal Mindfulness during instructional processes and MTS scores was close to 1 is thought to be related to the number of items in the subscales. 9 items of the 13-item scale are in the Intrapersonal Mindfulness subscale while 4 items are in the Interpersonal Mindfulness subscale. Therefore, it is thought that it will be useful to add representative items to the Interpersonal Mindfulness subscale and to re-examine the subscale correlations after these additions for further studies.

The internal consistency coefficient was found to be .64 for the Interpersonal Mindfulness subscale, to be .80 for the Intrapersonal Mindfulness subscale, and to be .78 for the whole scale. Considering that the internal consistency coefficient is a function of the number of items in the scale [29] and the strong correlation between Intrapersonal Mindfulness subscale and the total score of MTS $(r=.913)$, the opinion for the need to add items to the interpersonal conscious awareness subscale is also strengthened.

Finally, statistically significant correlations were found between the upper and lower $27 \%$ groups for item analysis; the positive correlation of this relationship indicated that the internal consistency of the MTS-TR was high. Moreover, the statistical significance of the re-test correlations with 3-week intervals revealed that MTS-TR is a reliable measurement tool.

In the light of all these findings, it can be seen that MTS is an appropriate measurement tool to measure the mindfulness of Turkish educators in teaching processes. The sample of the study was formed by convenient sampling. In terms of generalizability of the results, it is considered as appropriate to use the scale in researches using random or stratification sampling methods. In this study, the sample group consists of kindergarten, elementary school, middle school and high school teachers. Similar studies to be carried out in the future may be beneficial to the relevant literature through offering results from different educational institutions such as universities and vocational training centers. It is hoped that MTS will be used in studies on teaching processes and positive teaching.

\section{REFERENCES}

[1] Frank, J. L., Jennings, P. A., \& Greenberg, M. T. Validation of the Mindfulness in Teaching Scale. Mindfulness. 2016; $7(1): 155-163$.

[2] Baltaş, Z. ve Baltaş, A. (1998) "Stres ve Başa Çıkma Yolları" İstanbul, Remzi Yayınları.

[3] Boyle, G., J., Borg, M. G., Falzon, J. M., \& Baglioni, A. J. A Structural Model of The Dimensions Of Teacher Stress. British Journal of Educational Psychology. 1995; 65(2):49-67.

[4] Capel, S. A. A Longitudinal Study of Burnout in Teachers. British Journal of Educational Psychology. 1991; 61:36-45.

[5] Dick, R. V. \& Wagner, U. Stress and Strain in Teaching: A Structural Equation Approach. British Journal of Educational Psychology. 2001; 71:243-259.

[6] Jennings, P.A. \& Greenberg, M.T. The prosocial classroom: Teacher social and emotional competence in relation to child and classroom outcomes. Review of Educational Research. 2009; 79:491-525.

[7] Assor, A., Kaplan, H., Kanat-Maymon, Y., \&Roth, G. Directly controlling teacher behaviors as predictors of poor 
motivation and engagement in girls and boys: The role of anger and anxiety. Learning and Instruction. 2005; 15: 397-413.

[8] Hamre, B. K. Teachers' daily interactions with children: An essential ingredient in effective early childhood programs. Child Development Perspectives. 2014; 8(4): 223-230.

[9] Roffey, S. Changing behaviour in school: Promoting positive relationships and well-being. London: Sage; 2011.

[10] Jennings, P. Early Childhood Teachers' Well-being, Mindfulness, and Self-compassion in Relation to Classroom Quality and Attitudes towards Challenging Students. Mindfulness. 2015; 6(4):732-743.

[11] Kabat-Zinn, J. Full catastrophe living: Using the wisdom of your mind and body to face stress, pain, and illness. New York, Delacorte; 1990.

[12] Germer, C. K. Mindfulness: What is it: What does it matter? In Germer, R. D. Siegel, \& P. R. Fulton, editors. Mindfulness and psychotherapy. New York: Guilford Press; 2005.

[13] Grabovac, A. D., Lau, M. A., \& Willett, B. R. Mechanisms of mindfulness: A Buddhist psychological model. Mindfulness. 2011; 2(3): 154-166.

[14] Abenavoli, R. M., Jennings, P. A., Greenberg, M. T., Harris, A. R., \& Katz, D. A. The protective effects of mindfulness against burnout among educators. Psychology of Education Review. 2013; 37(2):57-69.

[15] Elreda, M., Jennings, P. A. DeMauro, A. A., Mischenko, P. P., \& Brown, J. L. Protective Effects of Interpersonal Mindfulness for Teachers' Emotional Supportiveness in the Classroom. Mindfulness. 2018, in press.

[16] Napoli, M. Mindfulness Training for Teachers: A Pilot Program. Complementary Health Practice Review. 2004; 9(1): $31-42$.

[17] Flook, L., Goldberg, S. B., Pinger, L., Bonus, K., \&, Davidson, R. J. Mindfulness for teachers: A pilot study to assess effects on stress, burnout and teaching efficacy. Mind Brain Educ. 2013; 7(3): 82-95.

[18] Franco, C., Manas, I., Cangas, A.J., Moreno, E., \& Gallego, J. Reducing teachers psychological distress through a mindfulness training program. Spanish Journal of Psychology. 2010; 13: 655-666.

[19] Gold, E., Smith, A., Hopper, I., Herne, D., Tansey, G., \& Hulland, C. Mindfulness-based stress reduction (MBSR) for primary school teachers. Journal of Child and Family Studies. 2010; 19:184-189.

[20] Singh, N. N., Lancioni, G. E., Winton, A. S. W., Karazsia, B. T., \& Singh, J. Mindfulness Training for Teachers Changes the Behavior of Their Preschool Students, Research in Human Development. 2010; 10(3): 211-233.

[21] Khoury, B. Mindfulness: Embodied and Embedded. Mindfulness. 2017; in press.

[22] Brown, K. W., \& Ryan, R. M. The benefits of being present: Mindfulness and its role in psychological well-being. Journal of Personality and Social Psychology. 2003; 84: $822-848$.
[23] Özyeşil, Z., Arslan, C., Kesici, Ş., Deniz, M. E. Bilinçli farkındalık ölçeğini Türkçe'ye uyarlama çalışması. Eğitimve Bilim. 2011; 36:226-227.

[24] Kim, E. \& Singh, N.N. Psychometric Properties of the Korean Version of the Mindfulness in Teaching Scale. Mindfulness. 2018; 9(1):344-351.

[25] Kline, B. R. Principles and practice of structural equation modeling (3rd ed.). New York: Guilford Press. 2011.

[26] Tabachnick. B. G., \& Fidell. L. S. Using multivariate statistics. 5th ed. Boston: Allyn and Bacon; 2006.

[27] Van de Vijver, F.J.R. \& Hambleton, R.K. Translating tests: some practical guidelines. European Psychologist. 1996; 1: 89-99.

[28] Hoyle, R. H. Confirmatory factor analysis. In H. E. A Tinsley \& S. D. Brown, editors. Handbook of applied multivariate statistics and mathematical modeling San Diego, CA: Academic Press. 2000; pp. 466-497.

[29] Cortina, J. M. What is coefficient alpha? An examination of theory and applications. Journal of Applied Psychology.1993; 78(1): 98-104. 